\title{
Promoters from Corynebacterium glutamicum : cloning, molecular analysis and search for a consensus motif
}

\author{
Miroslav Pátek, † Bernhard J. Eikmanns, Jaroslav Pátek $\ddagger$ \\ and Hermann Sahm \\ Author for correspondence: Bernhard J. Eikmanns. Tel: +49246161 3967. Fax: +492461612710.
}

Institut für Biotechnologie 1 , Forschungszentrum Jülich, D-52425 Jülich, Germany
Relatively limited information about promoter structures in Corynebacterium glutamicum has been available until now. With the aim of isolating and characterizing such transcription initiation signals, random Sau3A fragments of C. glutamicum chromosomal DNA and of the corynebacterial phage $\phi$ GA1 were cloned into the promoter probe vector $\mathrm{PEKPICm}$ and selected for promoter activity by chloramphenicol resistance of transformed C. glutamicum cells. The nucleotide sequence of ten chromosomal and three phage fragments was determined and the transcriptional start (TS) sites were localized by primer extension analyses. Additionally, the promoters of five previously isolated C. glutamicum genes were cloned and mapped. All of the isolated promoters were also functional in the heterologous host Escherichia coli. A comparative analysis of the newly characterized promoter sequences together with published promoters from $C$. glutamicum revealed conserved sequences centred about $35 \mathrm{bp}$ (ttGcca) and $10 \mathrm{bp}$ (TA.aaT) upstream of the TS site. The position of these motifs and the motifs themselves are comparable to the -35 and - 10 promoter consensus sequences of other Gram-positive and Gramnegative bacteria, indicating that they represent transcription initiation signals in $C$. glutamicum. However, the $C$. glutamicum consensus hexamer of the $\mathbf{- 3 5}$ region is much less conserved than in E. coli, Bacillus, Lactobacillus and Streptococcus.

Keywords: Corynebacterium glutamicum, promoter, consensus sequence

\section{INTRODUCTION}

The basic DNA sequence pattern of bacterial promoters recognized by the major RNA polymerase $\sigma$-factors (e.g. $\sigma^{\mathbf{7 0}}$ of Escherichia coli or $\sigma^{\mathrm{A}}$ of Bacillus subtilis) seems to be common to many bacterial species (Hawley \& McClure, 1983; Lisser \& Margalit, 1993; Pouwels \& Leer, 1993; Haldenwang, 1995; Helmann, 1995). The first proposal for a promoter consensus sequence was based on align-

\footnotetext{
†Present address: Institute of Microbiology, Academy of Sciences of the Czech Republic, Vídenská 1083, CZ-14220 Praha 4, Czech Republic.

$\ddagger$ Present address: Institute of Thermomechanics, Academy of Sciences of the Czech Republic, Dolejskova 5, CZ-18200 Praha 8, Czech Republic.

Abbreviations: CAT, chloramphenicol acetyltransferase; $\mathrm{Cm}$, chloramphenicol; Km, kanamycin; MCS, multiple cloning site; TS, transcriptional start; wt, wild-type.

The GenBank/DDBJ accession numbers for the sequences reported in this paper are X90356-X90368.
}

ment and statistical evaluation of $46 \mathrm{E}$. coli promoter sequences (Rosenberg \& Court, 1979). This consensus sequence which is partially conserved in all $\sigma^{70}$ and $\sigma^{\mathrm{A}}$ promoters comprises the two hexamers TTGaca and TAtaaT, separated by $17 \pm 1 \mathrm{bp}$ and located about $35 \mathrm{bp}$ and $10 \mathrm{bp}$, respectively, upstream of the transcriptional start (TS) site. The importance of these conserved -35 and -10 regions for the function of E. coli promoters was further confirmed by mutational analysis and by alignment of larger sets of promoters (e.g. Hawley \& McClure, 1983; Lisser \& Margalit, 1993; Harley \& Reynolds, 1987). For Gram-positive bacteria, a consensus sequence based on 29 vegetative promoters, mainly from the genera Bacillus and Staphylococcus, was proposed by Graves \& Rabinowitz (1986). In addition to -35 and -10 consensus sequences, which were identical to those found for E. coli $\sigma^{70}$ promoters, the authors detected a conserved TG motif located $1 \mathrm{bp}$ upstream of the -10 hexamer and, with a higher than $50 \%$ conservation rate, an A-track at 
position -43 relative to the TS site. The significance of these features was very recently corroborated by compilation and analysis of $236 \mathrm{~B}$. subtilis $\sigma^{\mathbf{A}}$-dependent promoter sequences (Helmann, 1995). TG dinucleotides at position $-15 /-14$ and $A+T$-rich regions upstream of the -35 region were also observed in several promoters from E. coli (Galas et al., 1985; Deuschle et al., 1986; Belyaeva et al., 1993) and from some other Grampositive bacteria, e.g. Lactobacillus and Streptococcus (Pouwels \& Leer, 1993; van der Vossen et al., 1987; Morrison \& Jaurin, 1990; Matern et al., 1994).

Corynebacterium glutamicum is a Gram-positive, nonsporulating micro-organism known particularly as a producer of various amino acids. Although a variety of $C$. glutamicum genes have been characterized (reviewed in Jetten \& Sinskey, 1995), knowledge on gene expression signals is still poor and the general structure of $C$. glutamicum promoters, i.e. a typical consensus sequence, has not as yet been defined. So far, the TS sites, and thus the promoter regions, of only a few $C$, glutamicum genes have been identified experimentally (Peoples et al., 1988; von der Osten et al., 1989; Marcel et al., 1990; Han et al., 1990; Börmann et al., 1992; Follettie et al., 1993; Heery \& Dunican, 1993; Schwinde et al., 1993; Eikmanns et al., 1994). Some of these promoter regions display in their -10 region a $6 \mathrm{bp}$ motif similar to the typical -10 consensus sequence of $\sigma^{70}$ and $\sigma^{\mathrm{A}}$ promoters. However, only one of the promoters, i.e. that of the $f d a$ gene (von der Osten et al., 1989), shows similarity to both the -10 and -35 consensus sequences and a proper distance of $18 \mathrm{bp}$ between them. According to the few data available, it seemed that promoter sequences in C. glutamicum differ from those of $E$. coli or B. subtilis or at least display less conformity with the typical promoter consensus pattern common to both Gram-negative and Gram-positive bacteria.

In this study we isolated 18 promoters from C. glutamicum and four from the temperate corynephage $\phi \mathrm{GA} 1$ (Sonnen et al., 1990) and mapped the respective TS sites. Then, using newly developed computer programs, we performed a comparative analysis of these promoter sequences together with the previously published ones to find a common pattern representing a corynebacterial promoter consensus sequence.

\section{METHODS}

Bacterial strains, plasmids and growth conditions. $C$. glutamicum wild-type (wt) (ATCC 13032), the restrictiondeficient C. glutamicum R163 (Brabetz et al., 1991) and E. coli DH5 (Hanahan, 1985) were used. For isolation of promoters, the promoter probe vector $\mathrm{pEKplCm}$ (Eikmanns et al., 1991) was employed. This vector carries the kanamycin $(\mathrm{Km})$ resistance gene and, downstream of the multiple cloning site (MCS), the promoterless cat gene with transcription terminators of the E. coli rrnB operon. The region between the MCS and the reporter gene contains translational stop codons in all three reading frames followed by the native ribosomal binding site of the cat gene. Further plasmids used were pJC20 containing the dap $A$ and $d a p B$ genes (Cremer et al., 1990), pBM1 containing the ilv $A$ gene (Möckel et al., 1992), pKK5-5 containing the ilvC gene (Keilhauer $\ell$ t al., 1993) and pKK7 containing the gene for a putative membrane protein (ORFMP) from $C$. glutamicum (Pátek et al., 1994). LB medium and $2 \times$ TY medium (Sambrook et al., 1989) were used for cultivation of E. coli and C. glutamicum, respectively. When appropriate, $\mathrm{Km}\left(50 \mu \mathrm{g} \mathrm{ml}^{-1}\right)$ was added to selective media. E. coli was grown aerobically at $37^{\circ} \mathrm{C}, \mathrm{C}$. glutamicum at $30^{\circ} \mathrm{C}$.

DNA isolation and manipulation. Chromosomal DNA from $C$. glutamicum was isolated as described previously (Eikmanns et al., 1994). DNA from phage $\phi$ GA1 (Sonnen et al., 1990) was kindly provided by H. Sonnen (TU Darmstadt). Plasmids from E. coli were isolated as described by Birnboim (1983), those from $C$. glutamicum by the same method with prior incubation $(1 \mathrm{~h}$, $37^{\circ} \mathrm{C}$ ) of the cells with lysozyme $\left(15 \mathrm{mg} \mathrm{ml}^{-\mathbf{1}}\right)$. E. coli was transformed by the $\mathrm{CaCl}_{2}$ method (Sambrook et al., 1989), C. glutamicum by electroporation (Liebl et al., 1989).

Restriction enzymes, T4 DNA ligase, Klenow polymerase, proteinase $\mathrm{K}$, DNase I, RNase A, RNasin and avian myeloblastosis virus (AMV) reverse transcriptase were obtained from Boehringer Mannheim or from Promega and used as instructed by the manufacturer.

DNA sequencing of the promoter fragments was done by the dideoxy chain termination method using the Sequenase 2.0 kit from USB Amersham Life Sciences. Primers were synthesized according to sequences of plasmid $\mathrm{pEKplCm}$ adjacent to the MCS with the Gene Assembler Plus and chemicals from Pharmacia. Primer $\mathrm{CmS}$ (GGTGGTATATCCAGTGAT) covers positions +30 to +13 and primer $\mathrm{CmR}$ (CCGGACGCGCGCTCCATG) positions -117 to -100 relative to the translational start of the cat gene.

RNA isolation and primer extension analysis. Total RNA from C. glutamicum was isolated as described previously (Eikmanns et al., 1994). For primer extension analyses of the promoter fragments cloned in $\mathrm{pEK \textrm {plCm }}$, the following primers were used: $\mathrm{CmS}$ (see above), $\mathrm{Cm} 2$ (TTGGCTGCAGGTCGACGG) covering positions -62 to $-79, \mathrm{Cm} 3$ (CGGCGGATTTGTCCTACT) covering positions +39 to +56 and $\mathrm{Cm} 4$ (GAAAATCTCGTCGAAGCTCG) covering positions +21 to +40 relative to the translational start of the cat gene in plasmid $\mathrm{pEK}$ plCm. For determination of the TS sites from the C. glutamicum genes $(\operatorname{dap} B, \operatorname{dap} A$, ilv $A$, ilv $C$ and orfMP) oligonucleotides complementary to the beginning of the individual genes were used as primers: O1-dapB (TCCGAGAACGCCAACCTTG), O2-dapB (CACGGCCTTTGGCTCCG), O3-dapB (GCTGCCACAATAGTTTGAC), O1-dapA (TCCGTGAATGGAGTAACC), O2-dapA (CCGGTCTTAGCTGTTAAAC), O1-ilvA (CACTCCTGGACTTTTCTC), O2-ilvA (AGCTCCGCTCCGCTAGCC), O1-ilvC (CAGTTCAATAGCCATGGG), O2-ilvC (GCCCCCCACTGTAAATCGTG), O1-orfMP (GGGGTGCGGAGCGCGATC) and O2orfMP (GCCCCATGCGATTGTTAA). All TS sites were determined using at least two primers.

Primer extension reactions were carried out as described by Eikmanns et al. (1994) using about $70 \mu \mathrm{g}$ total RNA from $C$. glutamicum, 20 pmol primer, $\left[\alpha_{-}^{35} \mathrm{~S}\right] \mathrm{dATP}$ and $5 \mathrm{U}$ AMV reverse transcriptase. The primer extension products and, for exact localization of the TS site, sequencing reactions performed with the same oligonucleotides used for the primer extensions were loaded and separated on a $6 \%(\mathrm{w} / \mathrm{v})$ polyacrylamide sequencing gel.

Enzyme assay and determination of MIC. To determine the chloramphenicol acetyltransferase (CAT) activity, C. glutamicum cells were grown in $60 \mathrm{ml}$ medium to exponential growth phase, washed twice in TS buffer ( $50 \mathrm{mM}$ Tris, $50 \mathrm{mM} \mathrm{NaCl}, \mathrm{pH} 7$ ) 
and resuspended in $2 \mathrm{ml}$ TS buffer. Cells were disrupted by sonication as described by Börmann et al. (1992) and after centrifugation for $30 \mathrm{~min}$ at $4{ }^{\circ} \mathrm{C}$ and $13000 \mathrm{~g}$, the supernatant was used as cell extract. The protein concentration was determined by the biuret method (Gornall et al., 1949). CAT activity was assayed photometrically at $412 \mathrm{~nm}$ and $37^{\circ} \mathrm{C}$ as described by Shaw (1975) in $1 \mathrm{ml}$ of a solution of $100 \mathrm{mM}$

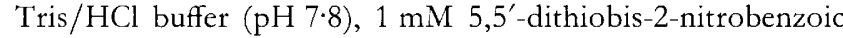
acid, $0.1 \mathrm{mM}$ acetyl $\mathrm{CoA}$, and $0.25 \mathrm{mM}$ chloramphenicol $(\mathrm{Cm})$. One unit of activity was defined as $1 \mu \mathrm{mol}$ of $\mathrm{Cm}$ acetylated $\min ^{-1}$.

The MIC of Cm on C. glutamicum and E. coli was determined on LB agar plates as described by Ozaki et al. (1984).

Computer analysis. In general two methods have been used to search for a consensus pattern in a set of promoter sequences. In the first method the sequences are aligned according to the TS site or according to an arbitrarily chosen region (e.g. the -10 region) and the most frequent bases in each column are counted (Hawley \& McClure, 1983; Graves \& Rabinowitz, 1986). The other method is based on the occurrence of a sequence motif, i.e. a k-letter pattern word, in a distinct region of sequences defined by the distance from the TS site (Galas et al., 1985). Since the sequence motifs sought may not occur in a completely conserved form, nor at a precise distance from the TS, two further parameters, $W$ and $m$, must be set: $W$ (window width) is the number of admitted consecutive columns to be examined at a time and $m$ is the minimal number of matches taken into account.

In our analysis we employed both these methods and combined their results. At first, all promoter sequences were aligned from base -50 to +10 with respect to the experimentally determined TS site. No prior assumptions about the significance of any sequence pattern or motif were made. In the procedure corresponding to the first method we developed and used the PROBAB program which, for a given number of sequences $(q)$ examines the number of base occurrences $n x$ (where $x=A, C$, $\mathrm{G}$ or $\mathrm{T})$ in each column $i(i=1-60)$ of the alignment. As a measure of orderliness of a particular column the program calculates the probability of base distribution for each column in a set of given sequences $(P)$ :

$$
P=\frac{q !}{n \mathrm{~A} ! \cdot n \mathrm{C} ! \cdot n \mathrm{G} ! \cdot n \mathrm{~T} !} \times \frac{1}{4^{q}}
$$

Local minimums of $P$ within the alignment indicate regions in which the sequences under consideration are more correlated (similar) than in other parts of the alignment.

For the other approach to sequence analysis, we developed the PROMSCAN program. The strategy of this program is very similar to that described by Galas et al. (1985) and it identifies conserved sequence motifs : from all possible combinations of $k$ bases, the algorithm localizes in each of the individual sequences a $k$-letter word (a sequence of $k$ bases) for which the number of matches within the alignment of all sequences is maximal within a given window. The sum of the maximal numbers of matches over all the sequences is then considered as a measure of conservation of the k-letter word examined. The k-letter word with the highest number of matches is considered the $k$-letter pattern word. The measure of significance of the $k$-letter pattern words is given by the relative score $S_{\text {rel }}$ which is the sum of matches in a given window related to its maximal value (at $k=6$ and $q=33$ the maximal value is $6 \times 33=198$ ). The PROBAB and PROMSCAN programs are available from M. Pátek.

\section{RESULTS}

\section{Cloning of promoter-carrying fragments from $C$. glutamicum and from phage $\phi \mathrm{GA} 1$}

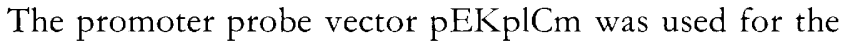
cloning and identification of promoter-active DNA fragments from the chromosome of $C$. glutamicum and from the corynebacterial phage $\phi \mathrm{GA} 1 .{ }^{C}$. glutamicum cells harboring $\mathrm{pEKplCm}$ were sensitive to $\mathrm{Cm}$ at $>2 \mu \mathrm{g}$ $\mathrm{ml}^{-1}$, indicating that no transcription from vector-borne promoters occurred.

Complete Sau3A digests of chromosomal DNA from wt C. glutamicum and of phage $\phi \mathrm{GA} 1$ were ligated into the BamHI site of $\mathrm{pEKplCm}$. The ligation mixtures were transformed into $E$. coli DH5 and transformants were selected on medium containing Km. About 10000 transformants of the ligation mixture containing C. glutamicum DNA and about 2000 of that containing $\phi \mathrm{GA} 1 \mathrm{DNA}$ were pooled. Plasmids from both pools were isolated, transformed into C. glutamicum R163 and the Km-resistant transformants obtained were screened for $\mathrm{Cm}$ resistance by replica-plating onto medium containing $\mathrm{Cm}$ at $5 \mu \mathrm{g}$ $\mathrm{ml}^{-1}$. Approximately $1 \%$ of the transformants containing pEKplCm with C. glutamicum DNA and $5 \%$ of those containing pEKplCm with $\phi \mathrm{GA} 1 \mathrm{DNA}$ grew on this medium, indicating that the fragments cloned in these $C$. glutamicum isolates contain functional promoters directing the transcription of the cat gene in $\mathrm{pEKplCm}$. Restriction analysis of plasmids from $20 \mathrm{Cm}$-resistant clones carrying $\mathrm{pEKplCm}$ with $C$. glutamicum DNA revealed insert sizes ranging from $70 \mathrm{bp}$ to $600 \mathrm{bp}$. Plasmid analysis of 20 clones carrying $\mathrm{pEKplCm}$ with $\phi \mathrm{GA} 1 \mathrm{DNA}$ revealed three types of inserts with sizes of about $100 \mathrm{bp}, 200 \mathrm{bp}$ and $250 \mathrm{bp}$, suggesting that we obtained three promotercarrying fragments from phage $\phi \mathrm{GA} 1$.

Besides shotgun-cloning of promoter-active fragments from the wt C. glutamicum chromosome and from phage $\phi \mathrm{GA} 1, \mathrm{DNA}$ fragments carrying the upstream regions of five previously sequenced $C$. glutamicum genes, dap $A$, $\operatorname{dap} B$, ilv $A$, ilv $C$ and $\operatorname{orf} M P$, were cloned. For this purpose, the $0.7 \mathrm{~kb}$ Pst $\mathrm{I}$ fragment (F-dapA) from plasmid $\mathrm{pJC} 20$, the $0.8 \mathrm{~kb} \mathrm{BclI-Sall}$ fragment (F-dapB) from plasmid pJC20, the $0.8 \mathrm{~kb} H$ indIII-Bam HI fragment (F-ilvA) from plasmid pBM1, the $0.8 \mathrm{~kb}$ SalI fragment (F-ilvC) from plasmid pKK5-5 and a 0.3 kb Sau3A fragment (F-orfMP) from plasmid $\mathrm{pKK} 7$ were ligated in the correct orientation into the MCS of $\mathrm{pEKplCm}$ and the resulting plasmids were introduced into $C$. glutamicum R163. All $C$. glutamicum transformants grew on medium containing $\mathrm{Cm}$ at $30 \mu \mathrm{g} \mathrm{ml}^{-1}$, indicating that the fragments contained the promoters responsible for transcription of the respective genes.

The 10 smallest promoter fragments obtained by shotgun cloning from the C. glutamicum chromosome (designated F1, F2, F10, F13, F22, F34, F37, F45, F64 and F75), the three promoter fragments obtained from phage $\phi \mathrm{GA} 1$ (PF101, PF104 and PF109) and the five promoter fragments from the C. glutamicum genes (F-dapA, F-dapB, F- 
Table 1. Size and promoter activity of DNA fragments isolated from the chromosome of C. glutamicum and from phage $\phi \mathrm{GA} 1$

Promoter activity was assayed by determining the $\mathrm{MIC}$ of $\mathrm{Cm}$ and by measuring the specific activity of CAT in cell extracts of $C$. glutamicum harbouring the respective $\mathrm{pEKplCm}$ derivative.

\begin{tabular}{|c|c|c|c|c|}
\hline $\begin{array}{l}\text { Fragment in } \\
\text { pEKplCm }\end{array}$ & $\begin{array}{l}\text { Fragment } \\
\text { size (bp) }\end{array}$ & $\begin{array}{l}\mathrm{MIC} \text { of } \mathrm{Cm} \text { in } \\
\text { C. } \text { glutamicum } \\
\quad\left(\mu \mathrm{g} \mathrm{ml}^{-1}\right)\end{array}$ & $\begin{array}{l}\text { MIC of Cm } \\
\text { in } E . \text { coli } \\
\left(\mu \mathrm{g} \mathrm{ml}^{-1}\right)\end{array}$ & $\begin{array}{l}\text { CAT activity in } \\
\text { C. glutamicum } \\
\text { [U (mg } \\
\left.\text { protein) }{ }^{-1}\right]^{*}\end{array}$ \\
\hline None & & $<2$ & 40 & $<0.001$ \\
\hline F13 & 81 & 35 & 360 & $0 \cdot 04 \pm 0 \cdot 01$ \\
\hline F22 & 115 & 45 & 240 & $0 \cdot 07 \pm 0 \cdot 01$ \\
\hline $\mathrm{F} 2$ & 157 & 45 & 240 & $0 \cdot 10 \pm 0 \cdot 02$ \\
\hline F75 & 72 & 50 & 200 & $0 \cdot 11 \pm 0 \cdot 01$ \\
\hline F-orfMP & 314 & 45 & 400 & $0 \cdot 12 \pm 0 \cdot 01$ \\
\hline F34 & 266 & 50 & 280 & $0.15 \pm 0.02$ \\
\hline $\mathrm{F} 1$ & 129 & 65 & 400 & $0 \cdot 16 \pm 0 \cdot 02$ \\
\hline F10 & 147 & 50 & 500 & $0 \cdot 17 \pm 0 \cdot 01$ \\
\hline PF109 & 206 & 45 & 450 & $0 \cdot 19 \pm 0.01$ \\
\hline F-dapA & 709 & 40 & 200 & $0 \cdot 20 \pm 0 \cdot 02$ \\
\hline F64 & 145 & 55 & 200 & $0 \cdot 23 \pm 0 \cdot 02$ \\
\hline F37 & 102 & 55 & 600 & $0 \cdot 25 \pm 0.02$ \\
\hline PF104 & 94 & 60 & 600 & $0.41 \pm 0.04$ \\
\hline PF101 & 252 & 55 & 600 & $0.42 \pm 0.07$ \\
\hline F-ilvA & $\sim 800$ & 50 & 360 & $0.92 \pm 0.05$ \\
\hline F-ilvC & 809 & 55 & 450 & $1 \cdot 12 \pm 0 \cdot 10$ \\
\hline $\mathrm{F} 45$ & 182 & 60 & 600 & $1 \cdot 16 \pm 0 \cdot 14$ \\
\hline F-dapB & 813 & 55 & 560 & $1 \cdot 70 \pm 0 \cdot 15$ \\
\hline
\end{tabular}

* The values are means \pm SD obtained from at least three independent experiments.

ilvA, F-ilvC and F-orfMP) were chosen for a more detailed analysis.

\section{Assessment of promoter activity in C. glutamicum and $E$. coli}

The relative strength of the cloned promoters was assessed by determining the $\mathrm{MIC}$ of $\mathrm{Cm}$ and by measuring the specific CAT activities in the different $C$. glutamicum clones. Whereas $C$. glutamicum harbouring plasmid pEKplCm was inhibited by $2 \mu \mathrm{g} \mathrm{Cm} \mathrm{ml}^{-1}$ and showed no detectable CAT activity, all clones harbouring pEKplCm with promoter fragments displayed $\mathrm{Cm}$ resistance to $>$ $30 \mu \mathrm{g} \mathrm{ml} \mathrm{m}^{-1}$ and CAT activities of 0.04 to $1.7 \mathrm{U}$ (mg protein $)^{-1}$ (Table 1). As also observed for E. coli and B. subtilis (Goldfarb et al., 1981; Close \& Rodriguez, 1982), the relationship between resistance level and CAT activity was not linear, although the reason for this discrepancy remains unclear. We previously showed that the copy numbers of $\mathrm{pEK} \mathrm{plCm}$ and promoter-carrying derivatives thereof are very similar (Eikmanns et al., 1991) and thus, major errors in evaluation of promoter strength due to different reporter gene dose can be ruled out.

To test whether the cloned $C$. glutamicum promoters function in E. coli, the MICs of Cm were also determined for E. coli DH5 harboring pEKplCm or its derivatives. As shown in Table 1, all plasmids containing promoter fragments conferred much higher $\mathrm{Cm}$ resistance to $E$. coli than plasmid $\mathrm{pEKplCm}$. Although higher by a factor of 5-10, the relative MIC values obtained for the E. coli clones roughly correlated to those observed in $C$. glutamicum clones carrying the respective plasmids. Fragments F37, PF104, PF101, F45 and F-dapB conferred relatively high $\mathrm{Cm}$ resistance to both $C$. glutamicum and $E$. coli, whereas fragments F13, F22, F2 and F-dapA led to relatively low levels of $\mathrm{Cm}$ resistance in both bacteria. The most conspicuous exception to this correlation is the promoter on fragment F64 which was relatively strong in $C$. glutamicum but one of the weakest in E. coli. However, the results indicated that all fragments isolated from the C. glutamicum chromosome and from phage $\phi \mathrm{GA} 1$ contain promoters which were functional in both $C$. glutamicum and E. coli.

\section{Sequencing of promoter-carrying fragments and mapping of TS sites}

The complete nucleotide sequences of the 13 shotguncloned promoter-carrying fragments were determined from both strands. The sizes of the fragments are given in Table 1 and promoter-relevant parts of the sequences, as 


\begin{tabular}{|c|c|c|}
\hline $\mathrm{P} 1-1$ & TCAACTAAGCGTCCCATAAGAACGAGGCGCAAGGCTGATGTACTCTGTCA & Á CCATGGATA \\
\hline$P 2-1$ & TGTACTCTGTCAACCATGGATAAACCGGTCGTGAGGGATGCAGCTCTGCT & G ATTTTTCGC \\
\hline P-2 & GTAATTGGGGCGCGTGGAGCCATTCGGCTTTCAGTAGTACTITATTTACT & A GCTGCTGTG \\
\hline P-10 & AGACCAAGGATGGCTITGAAGTTCTTGAGATCCGCAGTACGGTTATTAAT & A GAAAATGAT \\
\hline P-13 & GATCCGTCCCCGGGGAAGTGGGAAATGCIAAAATGGAACG & A CATTCGCAT \\
\hline P1-22 & CATTTTCTAATTTCGTGTGTAGCTTTGAATTGGCCTTGGTGAATCCAGGC & T TATGGTTAT \\
\hline P2-22 & GTGTGTAGCTTTGAATTGGCCTTGGTGAATCCAGGCTTATGGTTATCTCT & G CAGCTATTT \\
\hline P-34 & GAAACGTGGCGACTTATGGGATTGAATGCAAACGTGATGGGGTAGCGGAC & C CCAACCAAA \\
\hline$P-37$ & TCCTAATAAATATTGCGAGGGTTCGCGGGATTAATGTACTCTCGAAGGTT & G AACACAGGG \\
\hline$P-45$ & TTGGTCAGGGATTTTTTCCCGAGGGCACTAATTTTGCTAAAGTAAGTGAC & G AAGAAGTTC \\
\hline P-64 & AGATTCTGCGCGAGITCCGCCCACACGTCATCATTACCTATGATGAGAAC & G GCGGTTACC \\
\hline$P-75$ & TAGCGATTAGCGCGCGCTGAGCTTTAGTTTACAGCTAACATGAGGTGCAT & A AACAAAACG \\
\hline P1-101 & ACAATCGAACCGACGACACCGCACGCCCTCGATAACCTGGGTTGTGCGGT & T TTGTTATTC \\
\hline P2-101 & AACCTGGGTTGTGCGGTTTTGTTATTCCTTGAGTGAGTTCGIGGGGTTCT & C ATTTGGGTT \\
\hline P-104 & ATGAGCTGGCAGCGTATTTGACCGATCCGGACACCTGGGATAATGTGTGG & A TTTTGTCGG \\
\hline P-109 & GTGGAAGCCCATGAAGAGCACATCATGAAACTGTGGAGGTATTGACCGGT & G GATGAATTC \\
\hline $\mathrm{P}-O R F M P$ & TGACAGGTGCTACTTCGCGAGCAACTCTTTAGTCAACTACCCTGAATCAA & G TGCAAAGCA \\
\hline $\mathrm{P}-i I v A$ & ACCTATGCCAAAGTAGGTGCAATTCTAGGAGAAGATTACACTAGTCAACC & A TGAGTGAAA \\
\hline$P-i l v C$ & TGTGACTAGTCAAACACCGTCTAATTACATGTGTGTGGTAGAACAATAAT & G TAGTTGTCT \\
\hline $\mathrm{P}-\operatorname{dapA}$ & TGCGGGGTTGTTTAACCCCCAAATGAGGGAAGAAGGTAACCTTGAACTCT & A TGAGCACAG \\
\hline $\mathrm{P} 1-\operatorname{dap} B$ & TAGGTATGGATATCAGCACCTTCTGAACGGGTACGTCIAGACTGGTGGGC & G TTTGAAAAA \\
\hline $\mathrm{P} 2-d a p B$ & CACGAAAATGAAGGAGCATA & AGGTTGGC \\
\hline
\end{tabular}

P-hom AATTTCGgGGCTTIAAAGCAAAAATGAACAGCTTGGTCTATAGTGGCTAG G TACCCTTTT P-thrC CATATTTGAGACGgTGTGGGGGGTATTGTGTCACCCCTIGGGATAGgGT T ATATCCGTG P-fda AagGaATATCACACGACAAAAGTTGaGTGATGCAGGCATAATTGGCTAT A GGCAACTGA P-1ysa TAAGTATGGGTCGTATTCTGTGCGACGGGTGTACCTCGGCTAGAATTCT C CCCATGACA P1-ask AAAACACTCCTCTGGCTAGGTAGACACAGTTTATAAAGGTAGAGTTGAGC G GGTAACTGT P2-ask TGAATACGCTCGTGCATTCAATGTGCCACTTCGCGTACGCTCGTCTTATA G TAATGATCC P-gdh TTTTAATCTTTGIGGTCATATCTGTGCGACACTGCCATAATTTGAACGT G AGCAGTTAC P-glt TCTCACTTCGGATATGGCTAAACCGCATTTATCGGTATAGCGTGTTAACC G GACCAGATT P-gap ATGATTTTGCATCTGCTGCGAAATCTTTGTTTCCCCGCTAAAGTGAGGA C AGGTTGACA P-pgk CAATTGAATACCGGITGCCAGCGCCACACAATGTGTGGCAATCTGGGACA G TGCATCACA P-trp GGAAACTACGCAAGAACCCAAAAATGATTAATAATTGAGACAAGCTTCCC A CTTATGTGA
Fig. 1. Nucleotide sequences of $C$ glutamicum promoters aligned according to their TS sites. Putative -35 and -10 regions identified by the PROMSCAN program are underlined. The promoter sequences of hom, thrC, fda, lys A, ask, gdh, glt, gap, pgk and trp were taken from references cited in the text. deduced from primer extension analyses (see below), are shown in Fig. 1.

To map the precise TS sites within the shotgun-cloned promoter fragments, total RNA was isolated from $C$. glutamicum clones containing the promoter-carrying plasmids and used for reverse transcription with the $\mathrm{CmS}$, $\mathrm{Cm} 2, \mathrm{Cm} 3$ and/or $\mathrm{Cm} 4$ primers. For mapping the TS sites of $\operatorname{dap} A, \operatorname{dap} B, i l v A$, ilv $C$ and $\operatorname{orfMP}$, total RNA from wt $C$. glutamicum and gene-specific primers were used. In all cases at least one band was detected as primer extension product. As examples, the results of the experiments with fragments F2 and PF109, and of those with the genes orfMP and ilv $C$ are shown in Fig. 2. The nucleotide sequences of all promoters from nucleotide -50 to +10 with respect to the TS site were designated P-1, P-2, P-13 and so on (according to F1, F2, F13 and so on) and are aligned in Fig. 1. In the cases of F1, F22, PF101 and dapB the primer extension patterns indicated two distinct TS sites and thus the presence of two promoters (designated P1-1 and P2-1, P1-22 and P2-22, P1-101 and P2-101, and $\mathrm{P} 1-d a p B$ and $\mathrm{P} 2-d a p B$, respectively). The distances between the two TS sites were $38,14,33$ and 49 bp in the cases of F1, F22, PF101 and dapB, respectively. For 14 promoters we observed two or more adjacent or nearby bands apparently representing multiple TS sites from one promoter, e.g. in the cases of PF109 and F-ilvC (Fig. 2). The presence of multiple TS sites was previously observed for several promoters of E. coli and Streptomyces genes (Hawley \& McClure, 1983; Strohl, 1992) and, thus, is not uncommon.

In 26 cases out of 33 , the first transcribed base was either A or $G$. Such a preference for a purine residue as the TS site has been reported for E. coli and lactic acid bacteria (Hawley \& McClure, 1983; van der Vossen et al., 1987).

All promoter sequences (from position -50 to +1 ) 

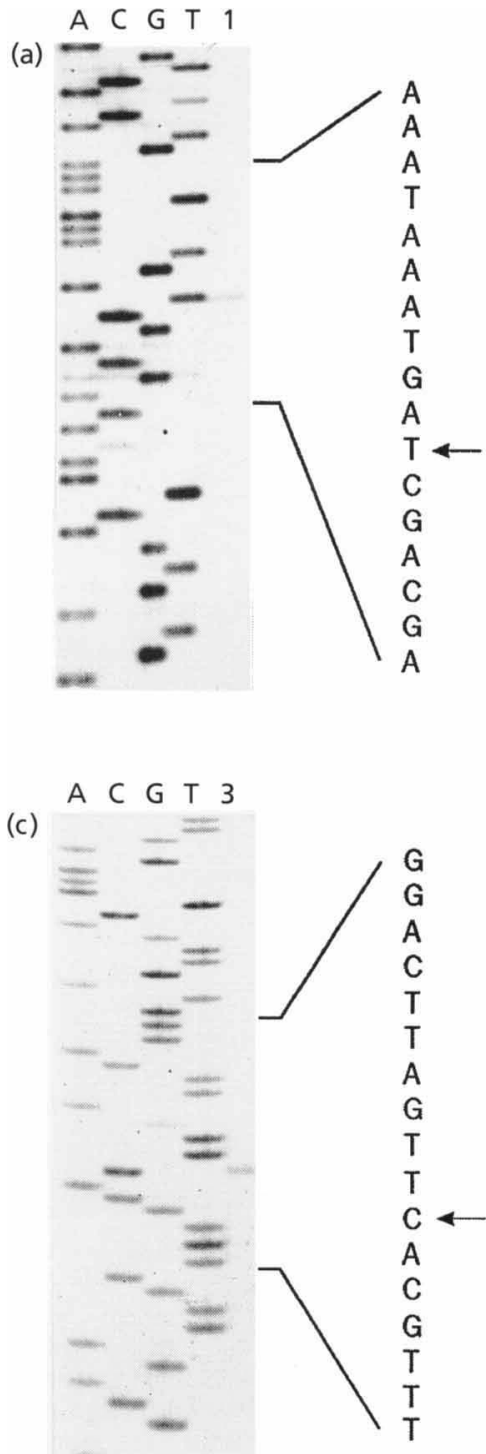

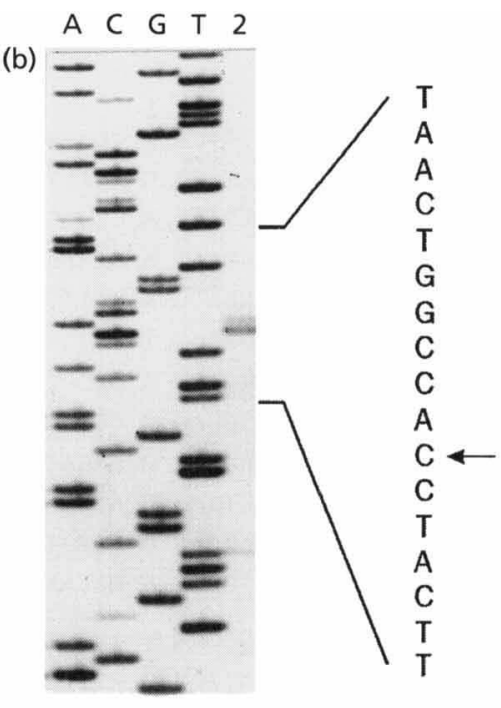

(d)

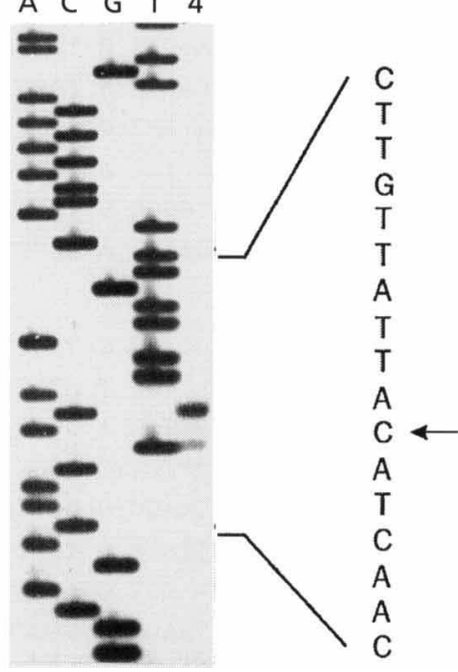

Fig. 2. Primer extension analyses of fragments F2 (a), PF109 (b), F-orfMP (c) and F-ilvC (d). The primer extension products are shown in lanes $1,2,3$ and 4 , respectively. Lanes $A, C, G$ and $T$ represent the sequencing reactions using the same primers as for the primer extensions. The relevant DNA sequences are shown on the right. Note that the sequences represent the coding strands and are thus complementary to those shown in Fig. 1. display a relatively high $\mathrm{A}+\mathrm{T}$ content of up to $67 \%$. In some promoters, e.g. P-orfMP, P-64, P-gdh and P-lys $A$, the region between positions -35 and -85 is extremely $\mathrm{A}+\mathrm{T}$-rich (65 to $78 \%$ ). Aside from the high $\mathrm{A}+\mathrm{T}$ content, a frequent occurrence of the dinucleotide $\mathrm{TG}$ (169 compared to the statistical average of 121) is the most apparent feature of the nucleotide composition of the whole set of promoter sequences.

\section{Analysis of promoter sequences}

To find conserved regions, the promoter sequences were aligned according to the TS site and analysed by our programs PROBAB and PROMSCAN. In those cases where two or more adjacent or nearby primer extension signals were found, we always took the strongest signal as the TS site. The analysis was done with the set of 22 promoters described here together with 11 published promoter sequences, i.e. P-bom (Peoples et al., 1988), P-thrC (Han et al., 1990), P-fda (von der Osten et al., 1989), P-lys $A$
(Marcel et al., 1990), P1-ask and P2-ask (Follettie et al., 1993), P-gdh (Börmann et al., 1992), P-glt (Eikmanns et al., 1994), P-gap and P-pgk (Schwinde et al., 1993), and P-trp (Heery \& Dunican, 1993) which are also aligned according to the TS site in Fig. 1. At first, the probabilities of the base distribution were calculated for all positions in the set by the рговав program. In the resulting histogram (Fig. 3a) the strongest signals (i.e. the lowest probability) were seen in the region of the TS site $(+1$ and -1$)$ and at positions -7 and -21 , slightly weaker signals at positions $-32,-34$ and -43 . The high value of $-\log (P)$ at position +1 corresponds to the preference for $A$ and $G$ nucleotides as the TS site (see above). In the next step, PROMSCAN was run on the same alignment of the sequences with various values for length of the $k$-letter word $(k)$, window width $(W)$ and lowest number of matches $(m)$. For various sets of parameters there was always a clear signal in the region from position -6 to -14 . For the parameters $k=6, W=11$ and $m=4$, a conspicuous region of $k$-letter pattern words with high $S_{\text {rel }}$ values was 

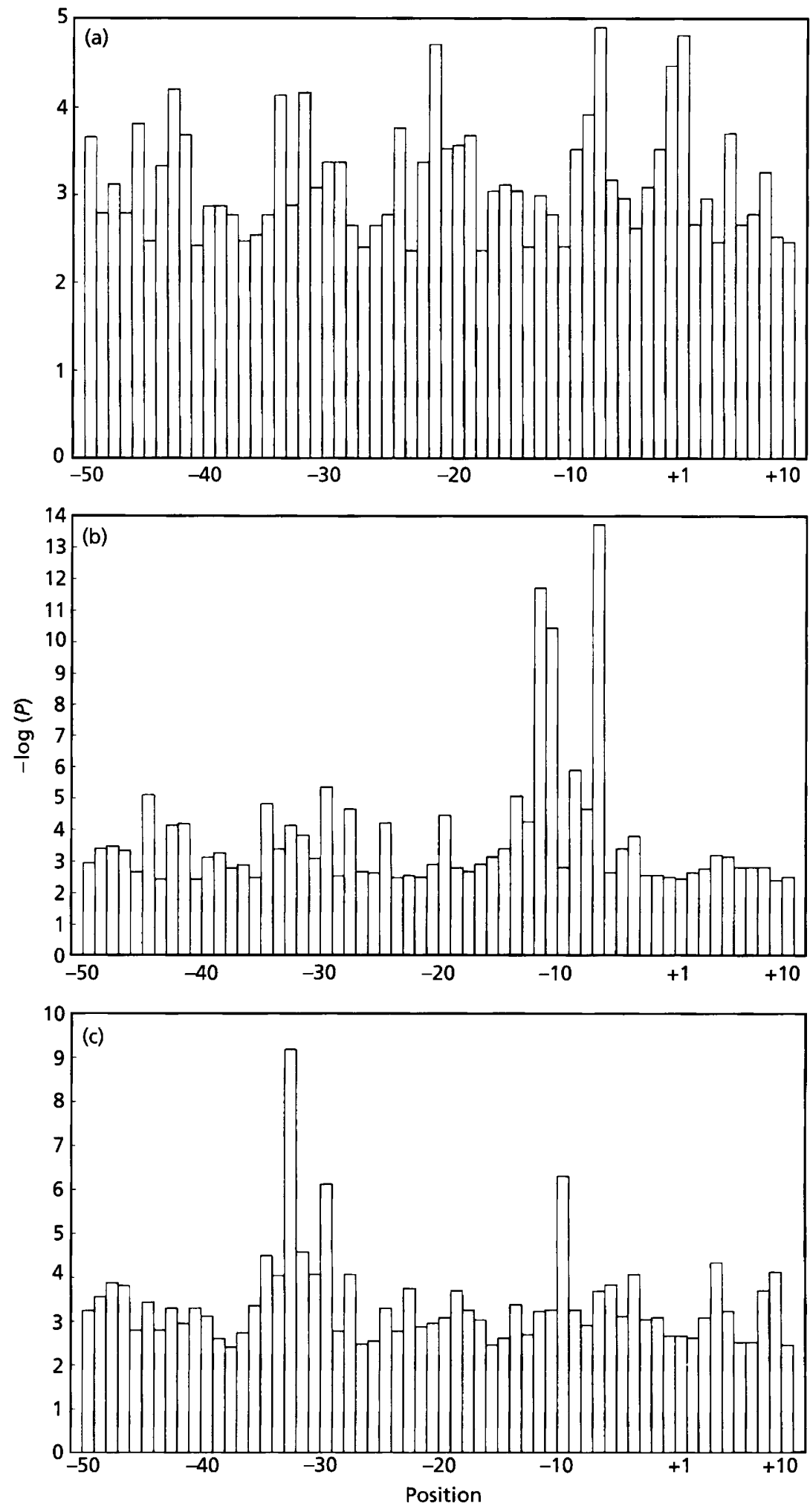

Fig. 3. Probability of base distribution $P$ calculated by PROBAB for each position in the promoter sequences aligned according to the experimentally determined TS sites (a), to the -10 region (b) and to the -35 region (c) as found by the PROMSCAN program. For convenience, the negative logarithm of $P[-\log (P)]$ is shown. detected $8-14$ bp upstream of the TS site (Fig. 4a). This region is referred to in the following as the -10 region. When the search for a hexamer $(k=6)$ was run at different $W$ and $m$ values ( $W=9-13 ; m=3-5$ ) the $k$-letter pattern words with the highest $S_{\text {rel }}$ values were also in the -10 region, the single $S_{\text {rel }}$ values being somewhat higher or lower. The hexamers with high $S_{\text {rel }}$ values were GGTAAA, GGTACA, TACAAT, TATAAT and TAGAGT and they were located at positions -12 to -9 relative to the TS site. 

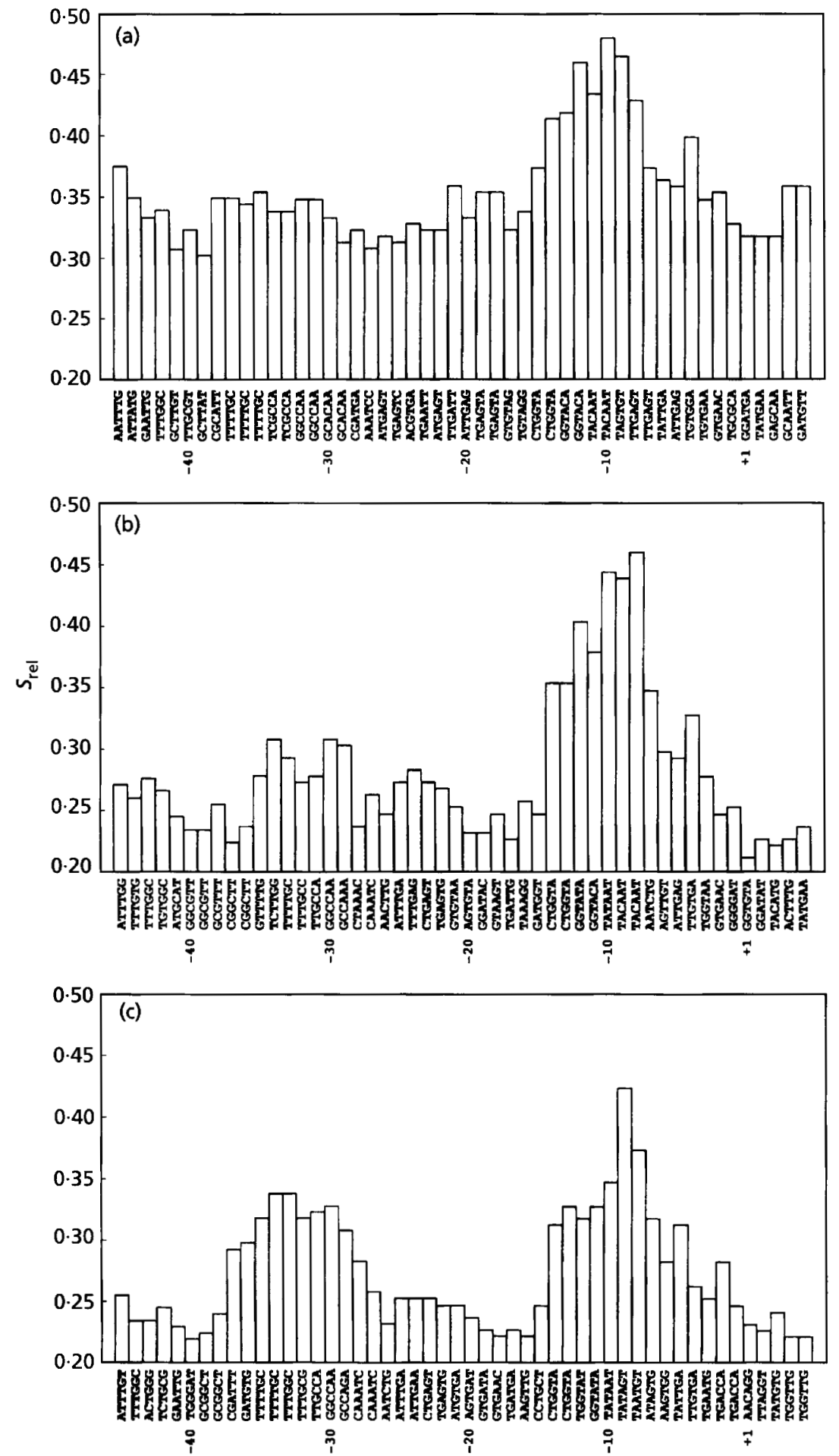

Fig. 4. Relative scores $\left(S_{\text {rel }}\right)$ of the $k$-letter pattern words for each position of the window in the promoter set aligned according to the experimentally determined TS sites (a), to the -10 region (b) and to the -35 region (c) as found by the PROMSCAN program. Parameters: $k=6 ; W=11$ in (a) and 9 in (b) and (c); $m=4$.
The results obtained by the alignment according to the TS site prompted us to align the promoter sequences according to the TACAAT or the most similar motif within the -10 region. With this new alignment the probability of the base distribution was again calculated by рRовав (Fig. 3b). Compared to the original alignment according to the TS site (Fig. 3a), several extraordinarily strengthened signals were obtained in the -10 region.
Using the same alignment and the PROMSCAN program with various $W$ and $m$ values, the signal peak in the -10 region was also stronger (e.g. Fig. 4b). Moreover, a second region of $k$-letter pattern words with above average $S_{\text {rel }}$ values was detected about 20 bp upstream of the -10 region. This region is referred to in the following as the -35 region. The hexamers in the maximum of the -10 region were GGTATA, GGTACA, TATAAT and 


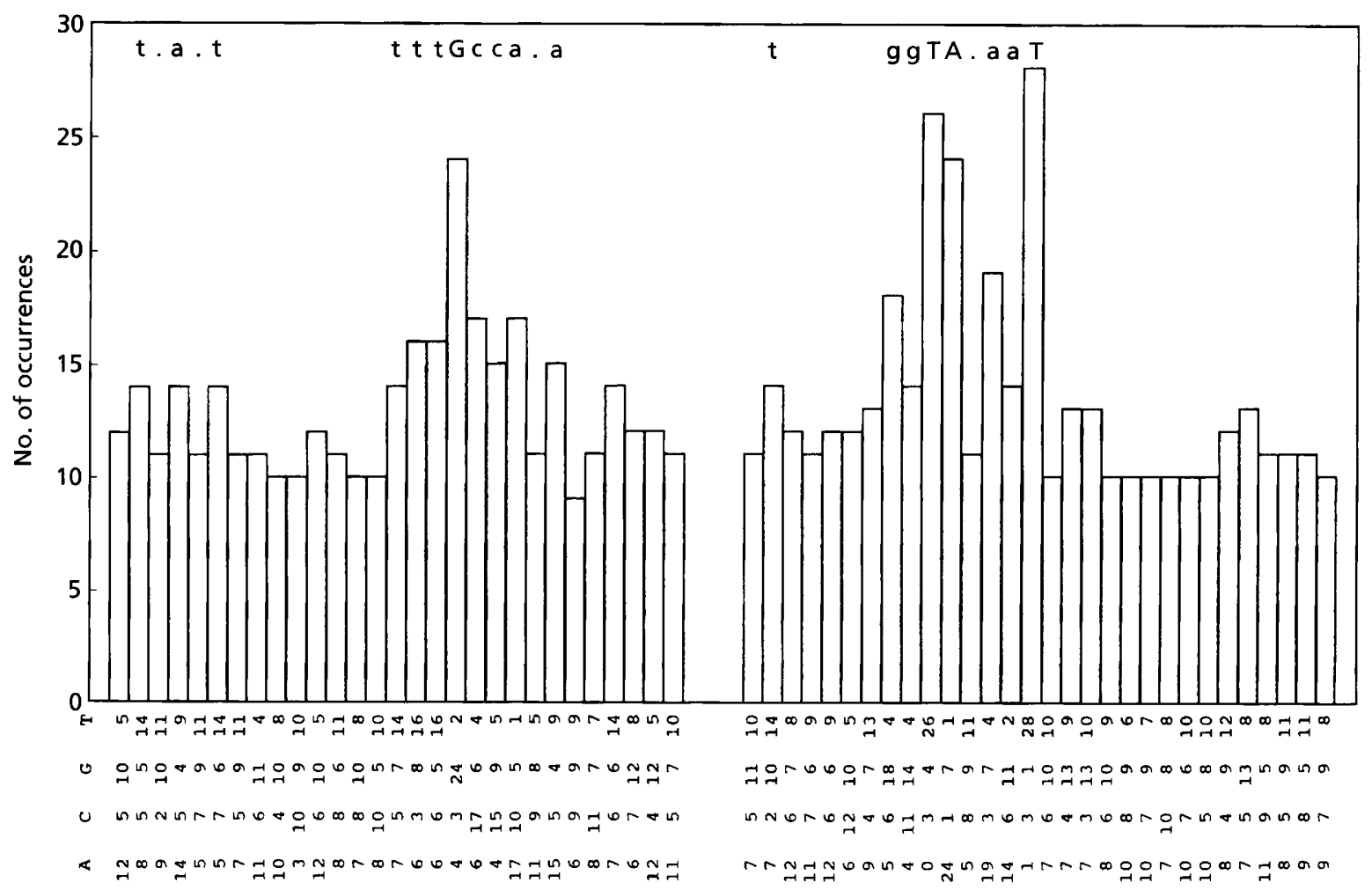

Fig. 5. Base distribution in C. glutamicum promoters aligned according to the -10 and -35 regions found by PROMSCAN. The break was introduced at the least correlated position. The number of occurrences of the most prevalent base at each position is shown in the histogram. The number of occurrences of each base at each position is shown at the bottom. The bases which occur in at least $42 \%$ of the promoters (i.e. 14 out of 33 ) at the same position are listed above the histogram. Bases occurring in more than $70 \%$ of the promoters (i.e. 23 out of 33 ) at the same position are capitalized.

TACAAT, those in the maximum of the -35 region were TCTTGG, TTTTGC, TTTGCC, TTGCCA, GGCCAA and GCCAAA. Essentially the same results were obtained for $W$ values of $8-11$ and for $m$ values of 3-5.

In the next step, the promoter sequences were aligned according to the sequence TTTTGCCAAA or the most similar motif in the -35 region and both the PROBAB and PROMSCAN analyses were done again. As expected, the plot of $P$ showed strongly enlarged signals in the -35 region. The promsCan analysis with $W$ values between 8 and 11 and $m$ values between 3 and 5 (e.g. Fig. 4c) showed identical or similar $k$-letter pattern words with relatively high $S_{\text {rel }}$ values in the -35 and -10 regions as in the previous analysis.

By comparing the location of the major signals from the PROBAB and PROMSCAN analyses, it can be seen that they are correlated both in their position and strength. To define a consensus sequence and the level of conservation of single bases within this consensus sequence, the widely used base distribution analysis (Hawley \& McClure, 1983) was performed. For this purpose, we aligned the promoter sequences according to the -10 and -35 motifs found by the PROMSCAN program (and underlined in Fig. 1) with a break at the least correlated position. As shown in Fig. 5 , the most conserved sequences were tttGcca.a in the -35 region and ggTA.aaT in the -10 region. It can also be seen from Fig. 5 that the level of conservation of individual bases in the -35 and -10 consensus sequences is quite different. However, we conclude that these two motifs characterize the regions carrying the main informational content of $C$. glutamicum promoters apparent from the sequences themselves.

\section{DISCUSSION}

The aim of our study was the isolation and molecular characterization of $C$. glutamicum promoters. Using the promoter probe vector $\mathrm{pEK \textrm {plCm }}$, a variety of promoteractive DNA fragments could be isolated. All 18 fragments tested also drove transcription of cat in E. coli, indicating that the isolated promoters were active in this organism too. This result was not unexpected since many of the genes cloned from C. glutamicum were expressed in E. coli as indicated by heterologous complementation of appropriate auxotrophs (reviewed in Jetten \& Sinskey, 1985). Conversely, several E. coli genes were efficiently expressed in C. glutamicum (e.g. Eikmanns et al., 1991; Pátek et al., 1989) and the E. coli tac, lacUV5, and trp promoters have been shown to be functional in corynebacteria (Morinaga et al., 1987). All these results indicate that the general structure of promoters from C. glutamicum is similar to that of promoters from E. coli. However, there were also reports on corynebacteria-specific 
promoters which were obviously not functional in E. coli (Cadenas et al., 1991).

The similarity of the primary structure of promoters from C. glutamicum with that of promoters from other bacteria was substantiated by comparative computer analysis. Both programs applied in this study showed that in our set of C. glutamicum promoters the most correlated region is located around $10 \mathrm{bp}$ upstream of the TS site and comprises the hexamer TA.AAT. This or a similar motif can be found in all promoters. Another conserved region was detected about $35 \mathrm{bp}$ upstream of the TS site. The consensus hexamer TTGCCA found in this region differs from the E. coli consensus TTGACA only in the fourth position. The role of the TTGCCA motif is not that obvious since it is clearly seen ( $>3 \mathrm{bp}$ matching) in only 14 promoters out of the 33 . In several others the motif was not easily discernible, indicating a lower conservation in C. glutamicum promoters. However, from the position relative to the TS site, from the spacing (a mean of $17.35 \mathrm{bp}$ ) and from the sequence of the two conserved hexamer motifs it is obvious that these signals in $C$. glutamicum promoters are comparable to the -10 and -35 promoter consensus sequences of E. coli (Hawley \& McClure, 1983; Lisser \& Margalit, 1993; Harley \& Reynolds, 1987) and other eubacteria, e.g. Bacillus (Helmann, 1995; Graves \& Rabinowitz, 1986; Moran et al., 1982), Lactobacillus (Pouwels \& Leer, 1993) and Streptococcus (van der Vossen et al., 1987; Morrison \& Jaurin, 1990). The significance of the C. glutamicum consensus motifs found by our analyses is corroborated by the fact that the tac promoter (11 out of 12 positions identical to consensus) was found to be very efficient in $C$. glutamicum (Eikmanns et al., 1991; Morinaga et al., 1987) and that an alteration of the -10 hexamer in the E. coli lac promoter from TATGTT to TATATT, thus increasing the similarity to the consensus sequence, led to higher efficiency of the promoter in C. glutamicum (Brabetz et al., 1991).

Aside from the -10 and -35 hexamers, other positions seem to be conserved in $C$. glutamicum promoters: a double $G$ next to the $5^{\prime}$ end of the -10 element, an $A$ residue $2 \mathrm{bp}$ downstream of and a $\mathrm{T}$ residue directly upstream of the -35 element (Fig. 5). In fact, the conserved bases near the -10 and -35 hexamers expand the consensus motifs to ggTA.aaT and tttGcca.a, respectively. An extended promoter consensus has been proposed for Gram-positive bacteria due to the presence of a TG motif found in the majority of Bacillus and Lactobacillus promoters upstream of or separated by $1 \mathrm{bp}$ from the -10 hexamer (Helmann, 1995; Graves \& Rabinowitz, 1986; van der Vossen et al., 1987; Matern $e t$ al., 1994). Eleven out of the 33 promoters analysed here contain a TG motif in the $5^{\prime}$ neighbourhood of the -10 hexamer and thus, the TG doublet next to the -10 hexamer might have significance for promoter function in C. glutamicum too. The relatively high $\mathrm{A}+\mathrm{T}$ content upstream of the -10 region also seems significant especially since the mean A + T content of $C$. glutamicum is only about $43.5 \%$ (Liebl, 1991). Many promoters from Gram-positive bacteria, as well as some strong promoters from E. coli, show an A + T-rich region upstream of the - 35 region (e.g. Helmann, 1995; Graves \& Rabinowitz, 1986; Moran et al., 1982) and it has been suggested that $\mathrm{A}+\mathrm{T}$-rich sequences, in particular A tracks, are responsible for intrinsic DNA curvatures upstream of the -35 region and thus for the activation of transcription (reviewed in Perez-Martin et al., 1994). Recently, Ross et al. (1993) showed that an A + T-rich segment at the -40 to -60 region of the E. coli $\mathrm{rrnB}$ P1 promoter, the socalled UP element, stimulates transcription from several promoters and these authors suggest that such elements function as a third recognition element for RNA polymerase in at least some bacterial promoters. However, whether the GG in front of the -10 hexamer and/or the relatively high $\mathrm{A}+\mathrm{T}$ content upstream of the -10 region is important for promoter activity in C. glutamicum remains to be studied.

In some Gram-positive bacteria, e.g. Bacillus and Streptococcus, most of the -10 and -35 promoter regions match their consensus sequences TATAAT and TTGACA, respectively, nearly perfectly (Helmann, 1995; Graves \& Rabinowitz, 1986; Morrison \& Jaurin, 1990; Moran et al., 1982). In contrast, this does not hold for the set of C. glutamicum promoters studied here. Several of the bases in the C. glutamicum promoter consensus motifs are only moderately conserved (see Fig. 5), indicating only relatively moderate conservation of the motif as a whole. Since the conservation level of promoter consensus sequences probably reflects the requirements of the major RNA polymerase $\sigma$-factor in a given organism (Moran $e t$ al., 1982), it was interesting to compare the degree of consensus conservation per position in our study with that in compilations of promoters from other bacteria. As shown in Table 2 , nearly all bases in the -35 and -10 consensus hexamers in the Bacillus, Lactobacillus and Streptococcus promoters are much more and those in the $E$. coli promoters are considerably more conserved than in the set of $C$. glutamicum promoters. These data suggest that the recognition specificity of the major RNA polymerase in the organisms listed decreases in the order Bacillus/Lactobacillus/Streptococcus $>$ E. coli $>$ C. glutamicum. It should be mentioned that the mean $\mathrm{A}+\mathrm{T}$ content of chromosomal DNA in these (groups of) organisms decreases in the same order (Balows $e t$ al., 1991). Thus, our data corroborate a presumption mentioned by Morrison \& Jaurin (1990), i.e. that recognition specifity of RNA polymerase(s) and the conformity of promoters with the $\mathrm{A}+\mathrm{T}$-rich consensus sequence might have evolved in a given organism by adaptation to the $\mathrm{A}+\mathrm{T}$ content of its chromosome. In further accordance with this presumption, a compilation of promoters from streptomycetes (mean A $+\mathrm{T}$ content of $30 \%$ ) revealed that their sequences are widely diverse and that only 29 out of 139 promoters show motifs similar to the TATAAT and TTGACA hexamers in their -10 and -35 regions (Strohl, 1992).

As deduced from CAT activity measurements in $C$. glutamicum, the promoters isolated in this study varied considerably in their strength. Since the activity of promoters in E. coli can be correlated to a major extent 
Table 2. Degree of consensus conservation in the -35 and -10 motifs in compilations of promoters from different organisms

Promoter compilations for the different organisms were taken from the following references: $C$. glutamicum, 33 promoters (this work); E. coli, 263 promoters, (Harley \& Reynolds, 1987); Bacillus subtilis, 237 promoters (Helmann, 1995); Lactobacillus, 30 promoters (Pouwels \& Leer, 1993); Streptococcus, 17 promoters (Morrison \& Jaurin, 1990).

\begin{tabular}{|c|c|c|c|c|c|c|c|c|c|c|c|c|}
\hline \multirow[t]{3}{*}{ Bacterium } & \multicolumn{12}{|c|}{ Percentage conservation of single nucleotides in the consensus motif of the: } \\
\hline & \multicolumn{6}{|c|}{-35 region } & \multicolumn{6}{|c|}{-10 region } \\
\hline & $\mathbf{T}$ & $\mathrm{T}$ & G & $\mathbf{A}^{*}$ & C & $\mathbf{A}$ & $\mathbf{T}$ & $\mathbf{A}$ & $\mathbf{T}$ & $\mathbf{A}$ & $\mathbf{A}$ & $\mathbf{T}$ \\
\hline C. glutamicum & 48 & 48 & 73 & 54 & 45 & 52 & 79 & 73 & 33 & 58 & 42 & 85 \\
\hline E. coli & 78 & 82 & 68 & 58 & 52 & 54 & 82 & 89 & 52 & 59 & 49 & 89 \\
\hline Bacillus subtilis & 87 & 83 & 78 & 64 & 51 & 58 & 94 & 96 & 60 & 78 & 74 & 94 \\
\hline Lactobacillus & 90 & 87 & 60 & 63 & 43 & 60 & 83 & 83 & 60 & 87 & 63 & 90 \\
\hline Streptococcus & 88 & 76 & 88 & 59 & 59 & 47 & 76 & 100 & 65 & 71 & 65 & 100 \\
\hline
\end{tabular}

* In the C. glutamicum -35 consensus sequence the fourth nucleotide is $\mathrm{C}$ instead of A. An A at this position was found in only 7 of the 33 promoters ( $21 \%$ conservation).

with their similarity to the -35 and -10 consensus hexamers (Hawley \& McClure, 1983), we assumed that the observed CAT activity roughly correlates with the identity score of a given promoter with the predicted consensus promoter sequence. However, such a correlation could not be recognized. This might be due to several reasons. (i) The different $5^{\prime}$-untranslated mRNA sequences may have differential effects on cat-mRNA translatability or stability. (ii) The measured CAT activity arose in some cases from two promoters present on the fragments. (iii) Sequences outside of the consensus hexamers (e.g. A + T-rich upstream regions) can modulate promoter activity significantly (e.g. Galas et al., 1985; Deuschle et al., 1986; Ross et al., 1993). (iv) Our set of promoter sequences may include regulated promoters. Many E. coli promoters under positive regulation show only random similarity to the -35 consensus motif (Raibaud \& Schwartz, 1984). The presence of such promoters in our alignment would weaken the correlation between activity level and similarity to the consensus. (v) Our set of promoters may include some which should be classified separately due to their recognition by alternative RNA polymerase $\sigma$-factors of $C$. glutamicum. So far, the presence of multiple $\sigma$-factors has not been reported for $C$. glutamicum, however, the presence of more than one $\sigma$ factor has been observed in many prokaryotic genera (Lonetto et al., 1992; Merrick, 1993). Aside from the predominant 'housekeeping' $\sigma^{70}$, E. coli possesses at least six further $\sigma$-factors (Helmann, 1991; Gross et al., 1992) and in Streptomyces coelicolor and B. subtilis there are at least six and nine, respectively, additional $\sigma$-factors each having a specific target promoter sequence (Haldenwang, 1995; Buttner, 1989). If distinct $\sigma$-factors are also present in $C$. glutamicum, different sequence motifs for optimal promoter recognition and transcription initiation can be expected. Thus, the identification and characterization of the corynebacterial housekeeping $\sigma$-factor and, if present, of additional $\sigma$-factors and the corresponding consensus sequences would lead to a more detailed picture of corynebacterial promoters.

It becomes clear from the data presented here that further work, e.g. stringent mutational and biochemical analysis of selected promoters, is necessary to gain detailed information on the structure-function relationship of promoters (or promoter classes) in C. glutamicum and thus a better understanding of gene expression in this industrially important organism.

\section{ACKNOWLEDGEMENTS}

We are grateful to E. Kleinertz for excellent technical assistance, to $H$. Sonnen and H. J. Kutzner for kindly providing $\phi \mathrm{GA} 1$ DNA, to S. Peters for preparing the photographs and to J. Carter-Sigglow for critical reading of the manuscript. M. Pátek gratefully acknowledges the assistance of a fellowship from the EC (ERB-CIPA-CT-92-0058). This work was supported by a grant from NATO (H'Tech.LG 940257).

\section{REFERENCES}

Balows, A., Trüper, H. G., Dworkin, M., Harder, W. \& Schleifer, K.H. (1991). The Prokaryotes. New York: Springer-Verlag.

Belyaeva, T., Griffiths, L., Minchin, S., Cole, J. \& Busby, S. (1993). The Escherichia coli cys $G$ promoter belongs to the 'extended -10 ' class of bacterial promoters. Biochem J 296, 851-857.

Birnboim, H. C. (1983). A rapid alkaline extraction method for the isolation of plasmid DNA. Methods Enzymol 100, 243-255.

Börmann, E. R., Eikmanns, B. J. \& Sahm, H. (1992). Molecular analysis of the Corynebacterium glutamicum gdh gene encoding glutamate dehydrogenase. Mol Microbiol 6, 317-326.

Brabetz, W., Liebl, W. \& Schleifer, K.-H. (1991). Studies on the utilization of lactose by Corynebacterium glutamicum bearing the lactose operon of Escherichia coli. Arch Microbiol 155, 607-612. 
Buttner, M. J. (1989). RNA polymerase heterogeneity in Streptomyces coelicolor A3(2). Mol Microbiol 3, 1653-1659.

Cadenas, R. S., Martín, J. F. \& Gil, J. A. (1991). Construction and characterization of promoter-probe vectors for Corynebacteria using the kanamycin-resistance reporter gene. Gene 98, 117-121.

Close, T. J. \& Rodriguez, R. L. (1982). Construction and characterization of the chloramphenicol-resistance gene cartridge: a new approach to the transcriptional mapping of extrachromosomal elements. Gene 20, 305-316.

Cremer, J., Eggeling, L. \& Sahm, H. (1990). Cloning the dap $A$ dapB cluster of the lysine-secreting bacterium Corynebacterium glutamicum. Mol Gen Genet 220, 478-480.

Deuschle, U., Kammerer, W., Gentz, R. \& Bujard, H. (1986). Promoters of Escherichia coli: a hierarchy of in vivo strength indicates alternate structures. EMBO J 5, 2987-2994.

Eikmanns, B. J., Kleinertz, E., Liebl, W. \& Sahm, H. (1991). A family of Corynebacterium glutamicum-Escherichia coli shuttle vectors for cloning, controlled gene expression, and promoter probing. Gene 102, $93-98$

Eikmanns, B. J., Thum-Schmitz, N., Eggeling, L., Ludtke, K. U. \& Sahm, H. (1994). Nucleotide sequence, expression and transcriptional analysis of the Corynebacterium glutamicum glt $A$ gene encoding citrate synthase. Microbiology 140, 1817-1828.

Follettie, M. T., Peoples, O., Agoropoulous, C. \& Sinskey, A. J. (1993). Gene structure and expression of the Corynebacterium flavum N13 ask-asd operon. J Bacteriol 175, 4096-4103.

Galas, D. J., Eggert, M. \& Waterman, M. S. (1985). Rigorous pattern-recognition methods for DNA sequences. J Mol Biol 186, 117-128.

Goldfarb, D. S., Doi, R. H. \& Rodriguez, R. L. (1981). Expression of Tn9-derived chloramphenicol resistance in Bacillus subtilis. Nature 293, 309-311.

Gornall, A. G., Bardawill, C. J. \& David, M. M. (1949). Determination of serum proteins by means of the biuret reaction. $J$ Biol Chem 177, 751-766.

Graves, M. C. \& Rabinowitz, J. C. (1986). In vivo and in vitro transcription of the Clostridium pasteurianum ferredoxin gene. J Biol Chem 261, 11409-11415.

Gross, C. A., Lonetto, M. \& Losick, R. (1992). Bacterial sigma factors. In Transcriptional Regulation, Vol. 1, pp. 129-176. Edited by S. McKnight \& K. Yamamoto. Cold Spring Harbour, NY: Cold Spring Harbor Laboratory.

Haldenwang, W. G. (1995). The sigma factors of Bacillus subtilis. Microbiol Rev 59, 1-30.

Han, K.-S., Archer, J. A. C. \& Sinskey, A. J. (1990). The molecular structure of the Corynebacterium glutamicum threonine synthase gene. Mol Microbiol 4, 1693-1702.

Hanahan, D. (1985). Techniques for transformation of E. coli. In DN A Cloning. A Practical Approach, Vol. 1, pp. 109-135. Edited by D. M. Glover. Oxford: IRL Press.

Harley, C. B. \& Reynolds, R. P. (1987). Analysis of E. coli promoter sequences. Nucleic Acids Res 15, 2343-2361.

Hawley, D. K. \& McClure, W. R. (1983). Compilation and analysis of Escherichia coli promoter sequences. Nucleic Acids Res 11, 2237-3355.

Heery, D. M. \& Dunican, L. K. (1993). Cloning of the trp gene cluster from a tryptophan-hyperproducing strain of Corynebacterium glutamicum: identification of a mutation in the trp leader sequence. Appl Environ Microbiol 59, 791-799.
Helmann, J. D. (1991). Alternative sigma factors and the regulation of flagellar gene expression. Mol Microbiol 5, 2875-2882.

Helmann, J. D. (1995). Compilation and analysis of Bacillus subtilis $\sigma^{\mathrm{A}}$-dependent promoter sequences: evidence for extended contact between RNA polymerase and upstream promoter DNA. Nucleic Acids Res 23, 2351-2360.

Jetten, M. S. M. \& Sinskey, A. J. (1995). Recent advances in the physiology and genetics of amino acid-producing bacteria. Crit Rev Biotecbnol 15, 73-103.

Keilhauer, C., Eggeling, L. \& Sahm, H. (1993). Isoleucine synthesis in Corynebacterium glutamicum: molecular analysis of the $i l v B$ ilv $N$-ilv C operon. J Bacteriol 175, 5595-5603.

Liebl, W. (1991). The genus Corynebacterium - nonmedical. In The Prokaryotes, Vol. 2, pp. 1157-1171. Edited by A. Balows, H. G. Trüper, M. Dworkin, W. Harder \& K.-H. Schleifer. New York: Springer-Verlag.

Liebl, W., Bayerl, A., Schein, B., Stillner, U. \& Schleifer, K.-H. (1989). High efficiency electroporation of intact Corynebacterium glutamicum cells. FEMS Microbiol Lett 65, 299-304.

Lisser, S. \& Margalit, H. (1993). Compilation of E. coli mRNA promoter sequences. Nucleic Acids Res 21, 1507-1516.

Lonetto, M., Gribskov, M. \& Gross C. A. (1992). The $\sigma^{70}$ family: sequence conservation and evolutionary relationships. $J$ Bacteriol 174, 3843-3849.

Marcel, T., Archer, J. A. C., Mengin-Lecreulx, D. \& Sinskey, A. J. (1990). Nucleotide sequence and organization of the upstream region of the Corynebacterium glutamicum lys A gene. Mol Microbiol 4, 1819-1830.

Matern, H. T., Klein, J. R., Henrich, B. \& Plapp, R. (1994). Determination and comparison of Lactobacillus delbrueckii subsp. lactis DSM7290 promoter sequences. FEMS Microbiol Lett 122, 121-128.

Merrick, M. J. (1993). In a class of its own - the RNA polymerase sigma factor $\sigma^{54}\left(\sigma^{\mathrm{N}}\right)$. Mol Microbiol 10, 903-909.

Möckel, B., Eggeling, L. \& Sahm, H. (1992). Functional and structural analyses of threonine dehydratase from Corynebacterium glutamicum. J Bacteriol 174, 8065-8072.

Moran, C. P. Jr, Lang, N., LeGrice, S. F. J., Lee, G., Stephens, M., Sonenshein, A. L., Pero, J. \& Losick, R. (1982). Nucleotide sequences that signal the initiation of transcription and translation in Bacillus subtilis. Mol Gen Genet 186, 339-346.

Morinaga, Y., Tsuchiya, M., Miwa, K. \& Sano, K. (1987). Expression of Escherichia coli promoters in Brevibacterium lactofermentum using the shuttle vector pEB003. J Biotechnol 5, 305-312.

Morrison, D. A. \& Jaurin, B. (1990). Streptococcus pneumoniae possesses canonical Escherichia coli (sigma 70) promoters. Mol Microbiol 4, 1143-1152.

von der Osten, C. H., Barbas, C. F., Wong, C. H. \& Sinskey, A. J. (1989). Molecular cloning, nucleotide sequence and structural analysis of the Corynebacterium glutamicum $f d a$ gene: structural comparison of $C$. glutamicum fructose-1,6-biphosphate aldolase to class I and class II aldolases. Mol Microbiol 3, 1625-1637.

Ozaki, A., Katsumata, R., Oka, T. \& Furuya, A. (1984). Functional expression of the genes of Escherichia coli in Gram-positive Corynebacterium glutamicum. Mol Gen Genet 196, 175-178.

Pátek, M., Krumbach, K., Eggeling, L. \& Sahm, H. (1994). Leucine synthesis in Corynebacterium glutamicum: enzyme activities, structure of $l e u A$, and effect of leuA inactivation on lysine synthesis. Appl Environ Microbiol 60, 133-140.

Pátek, M., Navrátil, O., Hochmannová, J., Nesvera, J. \& Hubácek, J. (1989). Expression of the threonine operon from Escherichia coli in 
Brevibacterium flavum and Corynebacterium glutamicum. Biotechnol Lett 11, 231-236.

Peoples, O. P., Liebl, W., Bodis, M., Maeng, P. J., Follettie, M. T., Archer, J. A. \& Sinskey, A. J. (1988). Nucleotide sequence and fine structural analysis of the Corynebacterium glutamicum hom-thrB operon. Mol Microbiol 2, 63-72.

Perez-Martin, J., Rojo, F. \& de Lorenzo, V. (1994). Promoters responsive to DNA bending: a common theme in procaryotic gene expression. Microbiol Rev 58, 268-290.

Pouwels, P. H. \& Leer, R. J. (1993). Genetics of lactobacilli: plasmids and gene expression. Antonie van Leewwenhoek 64, 85-107.

Raibaud, O. \& Schwartz, M. (1984). Positive control of transcription initiation in bacteria. Annu Rev Genet 18, 173-206.

Rosenberg, M. \& Court, D. (1979). Regulatory sequences involved in the promotion and termination of RNA transcription. Annu Rev Genet 13, 319-353.

Ross, W., Gosink, K. K., Salomon, J., Igarashi, K., Zou, C., Ishihama, A., Severinov, K. \& Gourse, R. L. (1993). A third recognition element in bacterial promoters: DNA binding by the alpha subunit of RNA polymerase. Science 262, 1407-1413.
Sambrook, J., Fritsch, E. F. \& Maniatis, T. (1989). Molecular Cloning. a Laboratory Manual, 2nd edn. Cold Spring Harbor, NY: Cold Spring Harbor Laboratory.

Schwinde, J. W., Thum-Schmitz, N., Eikmanns, B. J. \& Sahm, H. (1993). Transcriptional analysis of the $g a p-p g k-t p i-p p c$ gene cluster of Corynebacterium glutamicum. J Bacteriol 175, 3905-3908.

Shaw, W. V. (1975). Chloramphenicol acetyltransferase from chloramphenicol-resistant bacteria. Methods Envymol 43, 737-755.

Sonnen, H., Schneider, J. \& Kutzner, H. J. (1990). Characterization of $\phi \mathrm{GA} 1$, an inducible phage particle from Brevibacterium flavum. $J$ Gen Microbiol 136, 567-571.

Strohl, W. R. (1992). Compilation and analysis of DNA sequences associated with apparent streptomycete promoters. Nucleic Acids Res 20, 961-974.

van der Vossen, J. M., van der Lelie, D. \& Venema, R. (1987). Isolation and characterization of Streptococcus cremoris Wg2-specific promoters. Appl Environ Microbiol 53, 2452-2457.

Received 15 September 1995; revised 30 November 1995; accepted 13 December 1995. 